\title{
Identification of factors contributing for the transmission of common cold among students in Hawassa university main campus, Ethiopia
}

Common cold is a cosmopolitan disease and the most prevalent causes of disease by rhinoviruses. Assessment on the factors contributing for the transmission of common cold among students. In Hawassa University main campus was done between February and May. Data were collected using open and closed ended questionnaires from randomly and subjectively selected students. The collected data were analyzed by descriptive statistical methods using tables, frequencies and percentages. The first factor contributing for the transmission of common cold in the students of Hawassa University was bad scent of the toilet. The best methods used to treat the disease were using of hot drinks and garlic. There are many different factors that can contribute for the transmission of the common cold such as when infected person speaking and coughing, dust when rainy, dust from class and bad scent of toilet. Bad scent from the toilet is the first factor that contributed for the transmission of common cold. Therefore, Hawassa University should increase the quality and quantity of toilets.

\section{Keywords: common cold, factors, students, transmission.}

\section{Introduction}

A cold is a general term used to refer to a mild viral infection of the nose, throat, sinuses and upper airways. Despite its benign nature, it is a major cause of morbidity and mortality on a worldwide basis.

Several viruses have been associated with such illness; about $50 \%$ of all colds are caused by rhinoviruses. Corona viruses probably cause another 15 to $20 \%$. All together; probably more than 200 agents cause the common cold. But there are at least 113 serotypes of rhinoviruses alone. So, a vaccine effective against so many different pathogens does not seem practical [1].

Rhinoviruses infections are spread from person to person by viral contaminated respiratory secretions. The highest incidence of rhinovirus-associated illness occurs in September and October. The incubation period of rhinovirus infection is one to three days. Persons with low levels of type-specific anti body are asymptomatic but shed virus on reinjection. These with high anti body titers are immune to infection [2].

A common cold (coryza) is an acute, selflimited upper respiratory tract disorder caused by infection with the variety of RNA viruses, including more than 100 distinct rhinoviruses and several corona viruses. Colds are frequent and worldwide in distribution, spread from person to person by contact with infected secretions. Infection is more likely during the winter months in temperate areas and during the rainy seasons in the tropics, when spread is facilitated by indoor crowding. In the United States, children usually suffer six to eight colds per year and adults two to three [3].

Generally, common cold is a cosmopolitan disease that can distribute in the world wide. The effect of disease is also well known in Africa as well as in Ethiopia. There are many students who have been suffered by common cold in Hawassa University. According to Hawassa University's Students Clinic report that the prevalence of common cold is maximum during the rainy season or from October to January taken from Hawassa University student's clinic, 2015.

Obviously Students who learn at higher levels of educations have enough awareness about the factors contributing for the transmission of common cold. Even though these students have enough information about the factors that

\section{Tegegne Bayih ${ }^{1 *}$ and Yosef Mitiku²}

${ }^{1}$ Researcher and Instructor at Hawassa University, Hawassa, Ethiopia ${ }^{2}$ Hawassa University P.O. Box 05 Hawassa, Ethiopia

*Author for correspondence:

tegegnebayih@gmail.com 
enhance the transmission of the common cold, there were students who had been suffered by common cold. Therefore, the current study was conducted to assess the factors contributing for the transmission of common cold among Hawassa University main campus students.

\section{Statement of the problem}

The common cold is one of the viral infections of the respiratory tract that is prevalent in Hawassa University. It is affecting the health of students and somewhat of workers of our university. If it continues in the same rate, it may affect the quality of education and the result of the students. Hence, solutions should be provided before the common cold causes different problems in the University. So, one of the solutions to this problem is conducting a research regarding what are the major factors contributing for the transmission of the disease in our university. Therefore, the study was conducted to assess the factors contributing for the transmission of common cold among Hawassa University Main Campus students.

\section{Objectives of the study}

To identify the factors contributing for the transmission of common cold and to recognize the ways of treatments given to common cold

\section{Significance of the study}

The study was important to manage the factors that contribute for transmission of common cold.

The study was also important for the prevention of common cold .

The study will teach members of Hawassa university main campus students how to prevent their selves after and before suffered by common cold.

\section{Materials and Methods}

\section{- Description of the study area}

The study was conducted at Hawassa University main campus. Hawassa city is the administrative center of sidama zone as well as the seat of the Southern Nations nationalities and Peoples Regional state of Ethiopia which is located $270 \mathrm{~km}$ south of Addis Abeba via Debre zeit, $130 \mathrm{~km}$ east of Sodo and $75 \mathrm{~km}$ north of Dilla. Hawassa has a latitude and longitude 703 'N380 28'E/7.05N 38.4670E and an elevation of $1708 \mathrm{~m}$. According to the of Housing and population census of May 2007 current population of Hawassa is estimated about 292,412 people, out of which 150,426 are males and 141.986 are females with the annual population growth rate of $4.02 \%$. There are intensive and diversified modern investments activities such as tourism, social service, real estate development, and industries. Hawassa is center for high level education and training in the region as well.

The main mission of Hawassa University is to be one of the leading higher institutions of teaching and learning in Ethiopia and to continually improve the relevance and quality of education, research and consultancy services to meet the development needs of the society. (www.hawassaonline.com 2014)

\section{- Sample size and sampling techniques}

From the total of Hawassa university main campus students, 70 respondents were selected randomly and 10 frequently affected students were selected subjectively.

\section{Data collection}

Data were collected from primary data through questionnaire and questionnaires distributed for

Randomly selected respondents.

\section{- Data analysis}

After collecting the necessary data, data were organized, summarized and analyzed by descriptive statistical methods using tables, frequencies and percentages.

\section{Results}

\section{- Back ground of the respondents}

The higher number (49) of respondents was males and high number (72) of respondents lied in the age group between 18 and 23 (TABLE 1 ).

\section{- Plants used to treat common cold}

Garlic (Allium sativum) was the most common plant used to treat common cold and a few participants used "Nigella sativa" to treat it (TABLES 1-4).

Methods used to prevent common cold before the person is infected

According to the TABLE 5 below, the 


\begin{tabular}{|l|l|l|l|}
\hline \multicolumn{2}{|c|}{ TABLE 1. Demographic features of participants. } \\
\hline \multirow{4}{*}{ Alternatives } & & \multicolumn{1}{c|}{ Frequencies } & \multicolumn{1}{c|}{ Percentage } \\
\hline \multirow{4}{*}{ Aex } & Male & 49 & $61.25 \%$ \\
\cline { 2 - 4 } & Female & 31 & $38.75 \%$ \\
\cline { 2 - 4 } & Total & 80 & $100 \%$ \\
\hline \multirow{4}{*}{ Age } & $18-23$ & 72 & $90 \%$ \\
\cline { 2 - 4 } & $24-29$ & 5 & $6.25 \%$ \\
\hline & $30-35$ & 3 & $3.75 \%$ \\
\cline { 2 - 4 } & $>35$ & 0 & $0 \%$ \\
\hline & Total & 80 & $100 \%$ \\
\hline
\end{tabular}

\section{TABLE 2. Factors contributing for the transmission of common cold.}

\begin{tabular}{|l|c|c|}
\hline Factors & Frequencies & Percentage \\
\hline Speaks with infected person & 32 & $29.36 \%$ \\
\hline Bad scent of toilet & 51 & $46.79 \%$ \\
\hline Dust when rainy & 12 & $11.01 \%$ \\
\hline Dust in the class and dorm & 14 & $12.84 \%$ \\
\hline Total & 109 & $100 \%$ \\
\hline NB: Respondents selected more than one alternative based on the question \\
\hline
\end{tabular}

\begin{tabular}{|c|c|c|}
\hline TABLE 3. Ways of treatment to common cold. \\
\hline Methods & Frequencies & Percentages \\
\hline Hot drinks & $5 ?$ & $64.58 \%$ \\
\hline Doing exercises & 12 & $12.5 \%$ \\
\hline Traditional medicines & 19 & $19.79 \%$ \\
\hline Modern medicines & 3 & $3.12 \%$ \\
\hline Totals & 96 & $100 \%$ \\
\hline Respondents selected more than one alternative based on the question. \\
\hline
\end{tabular}

\begin{tabular}{|l|l|l|l|}
\hline TABLE 4. Name of plants used to treat common cold. \\
\hline List of plants & Frequencies & Percentages & Ways of taking trearment \\
\hline Allium sativum & 32 & $35.95 \%$ & Put pieces in nose \\
\hline Zingiber officinale & 30 & $33.70 \%$ & Drinking boiled crushed \\
\hline Eucalyptus globules & 8 & $8.99 \%$ & Drinking boiled crushed \\
\hline Ocimum latifolium & 4 & $4.49 \%$ & Drinking boiled crushed \\
\hline Ruta chalepensis & 9 & $10.11 \%$ & Drinking boiled crushed \\
\hline Citrus aurantifolia & 5 & $8.62 \%$ & Drinking boiled crushed \\
\hline Nigella sativa & 1 & $1.12 \%$ & Drinking boiled crushed \\
\hline Total & 89 & $100 \%$ & Effective \\
\hline NB: Respondents selected more than one alternative based on the question. \\
\hline
\end{tabular}

\begin{tabular}{|l|c|c|}
\hline \multicolumn{1}{|c|}{ TABLE 5. Pre-treatment of common cold. } \\
\hline Destroy/burn waste materials & Frequencies & Percentage \\
\hline Keeping personal hygiene & 14 & $12.5 \%$ \\
\hline Avoiding contact with patients & 35 & $31.25 \%$ \\
\hline Say in dorm or class when there is a rain & 26 & $23.21 \%$ \\
\hline No use a toilet that has bad scent & 6 & $5.35 \%$ \\
\hline Total & 31 & $27.67 \%$ \\
\hline
\end{tabular}

best method of common cold prevention was keeping of personal hygiene and the lowest prevention method was staying in dorm or class when there is rain.

\section{Ways to manage personal hygiene}

The highest number of personal hygiene management was cleaning class/dorm and motivating others as to clean and the smallest 
TABLE 6. The techniques of managing personal hygiene.

\begin{tabular}{|l|c|c|}
\hline Techniques of managing & Frequencies & Percentages \\
\hline Washing hands after contact with patients & 18 & $17.65 \%$ \\
\hline Cleaning the mucus by using soft and cotton cloth & 27 & $26.47 \%$ \\
\hline Cleaning the mucus by hand & 5 & $4.90 \%$ \\
\hline Cleaning class/dorm and motivating others as to clean & 52 & $50.98 \%$ \\
\hline Total & 102 & $100 \%$ \\
\hline
\end{tabular}

\begin{tabular}{|c|c|c|}
\hline Safety & Frequencies & Percentage \\
\hline Covering mouth when coughing and speaking & 51 & $40.47 \%$ \\
\hline Sit far from partner during cough & 10 & $7.93 \%$ \\
\hline Open windows of rooms during cough & 30 & $23.81 \%$ \\
\hline Cover drops of sputum with soil & 17 & $13.49 \%$ \\
\hline Avoid hand shaking and shaking greeting & 18 & $14.28 \%$ \\
\hline Total & 126 & $100 \%$ \\
\hline
\end{tabular}

ways of managing was cleaning mucus by using hand (TABLE 6)

\section{Common cold safety used to prevent transmission to others}

The best safety to control the transmission of common cold to others was covering mouth during coughing and speaking time. The less common safety was sitting far from infected partner

As TABLE 7 showed that the basic possibilities of safety of common cold informed from informants according to questions, for example, covering mouth to protect moisture droplet of virus, sit far from partner during cough, open windows of room during cough and avoid shaking of greeting were provided information from information. Students have said that within the university there was high frequency of transmission because of there was high social interaction among them consequently, which results high infections had been occurred.

\section{Discussions}

In the present study female male respondents were participated who are selected for the purpose of get appropriate information, As showed in TABLE 2 there were factors that had contributions for the transmission of cold. For instance, Bad scent of toilet and Bad scent of toilet were major factors for the transmission of common cold. Additionally, Dust in the class and dorm and Dust when rainy had their own contributions. On the other hand, common cold treatments were identified according to the respondents. Hot drinking and traditional plants had major effect for treatment of the virus and modern medicine had been rarely used removal of infections. For example, Garlic (Allium sativum and ginger (Zingiber officinale) were identified as the most importance treatment in the present study.

In the present study pretreatments of common cold was also investigated, keeping personal hygiene, avoiding contact with patients and Not use a toilet that has bad scent were techniques which are commonly used among students.

As the study revealed, the highest sources of common cold was from bad scent of the toilet because, the toilet is an area of highly contaminated surfaces by many viruses and other microorganisms. So, common cold can be caused from any contaminated places. This concept is also supported by scholars or researchers [4]. In other way, the highest methods used to treat this viral disease was using hot drinks and garlic, because hot drinks may decrease the capacity of the common cold by decreasing/inhibiting the replication rate of cold virus and the amount of nasal mucus. Many researchers also supported to using of hot drinks as method of treatment to common cold [5]. The same to this, garlic is also containing antiseptic properties and it may decrease the propagation of the viruses. This study also line with the work of other researchers [6]. In the other hand, the highest prevention and management of common cold was keeping of personal hygiene and cleaning class/dorm and motivating others as to clean. The study also revealed that the best safety measure to control the transmission of common cold to 
others was covering mouth during coughing and speaking to other, Although materials that are contaminated by infected person should not be shared together such as: water bottles, drinking glasses, cups, eating utensils and straw, these methods may be used to control the transmission of the disease to the healthy person. This idea also supported by many researchers [7].

The present study had agreement with the idea [8] and revealed that three proposed mechanisms for transmission of the common cold: small particle aerosols produced from coughing that are inhaled by another person, large particle droplets produced from saliva expelled during a sneeze that land on the conjunctivae or nasal mucosa of another person, or self-inoculation of one's own conjunctivae or nasal mucosa after touching a person or object contaminated with cold virus. In the experimental setting, sneezing (large-particle aerosol) has been shown to be a very inefficient method of transmission of rhinovirus. There were several studies have been investigated on common cold indicated as followed. Small-particle aerosol transmission of rhinovirus has been shown to occur but also appears to be inefficient [9]. Substantial evidence from the experimental setting suggests that rhinovirus can be transmitted efficiently via self-inoculation. Rhinovirus is excreted in nasal secretions but is only present minimally in saliva. Fingers and hands are frequently contaminated with rhinovirus, as are telephones and other everyday objects [10]. In experimental settings, hand-to-hand transfer and hand-tosurface to- hand transfer have been shown to be feasible mechanisms for transfer of rhinovirus to susceptible individuals. Once the hands are contaminated with cold virus, self-inoculation readily occurs when a person touches his own nose or eyes with the contaminated hand or fingers [11]. Self-inoculation also appears to be an effective method of rhinovirus transmission in the home environment because secondary transmission in the home can be reduced if selfinoculation is interrupted. In one study, mothers whose fingertips were treated with virucidal $2 \%$ aqueous iodine were much less likely to become infected than mothers whose fingertips were treated with placebo.

Similarly, the use of virucidal tissues to interrupt viral transfer has been shown to decrease secondary transmission of colds in the home modestly [12].

\section{Summary}

There are many different factors that can contribute for the transmission of common cold such as when infected person is speaking and coughing, dust when rainy, dust from class or dorm, bad scent from toilet. There are various traditional plants such as Allium sativum, Zingiber officinale; Eucalyptus globules, Citrus aurantifolia and Ocimum latifolium are used to treat common cold. Moreover, using of hot drinks, traditional and modern medicines, doing exercises are the ways used to treat common cold. Personal hygiene and keeping the neatness of the environment were among the pre-treatment methods used to treat common cold.

\section{Recommendations}

Based on the study result, I want to include the following recommendations.

Bad scent from the toilet is the first factor that contributed for the transmission of common cold. Therefore, Hawassa University should increase the quality and quantity of toilets.

Students have used some plants to treat common cold. As a result, the university should provide a sufficient amount of these plants in lounges and cafes.

$>$ Dust from the environment can cause common cold. Hence, students should try to put materials used to clean mucus in dust bin.

$>$ As Keeping of personal hygiene is one of the foremost methods in prevention and management of common cold, students should give a great emphasis on it.

Infected person can transmit common cold to healthy person. Therefore, infected persons should cover their mouth when they are coughing and speaking.

\section{Acknowledgements}

Authors begin by thanking the Almighty God for his approval inspiration and divine guidance that made this study possible, secondly, authors would also like to express sincere appreciation to all of the questionnaire respondents for their valuable cooperation's. Lastly, thank to Hawassa University and MoE for giving this opportunity and the partial fulfillment of BSc degree for YM. 


\section{References}

Gerard JT, Berdell R, Funke, et al. Microbial disease of the respiratory system, microbiology, an introduction, 9th Edition, India. pp. 717 (2009).

Robert FB Rhinoviruses. Basic medical microbiology, 5 Edition, United States of America. pp. 432 (1995).

Rubin E, Reisner HM Essentials of Rubin's pathology, 5th edition, America, New York. (2009).

Roxas M, Jurenka J. Colds and influenza: a review of diagnosis and conventional, botanical, and nutritional considerations. Altern. Med. Rev. 12(1), 25-48 (2007).
Marjoria KC, Kathleen PT. Infectious disease affecting the respiratory system, microbiology a systems approach, avenue of American, New York. 656-657 (2006).

Ketema T, Etana D, Adugna T. Ethno-medicinal study of plants used for treatment of human and livestock ailments by traditional healers in South Omo, Southern Ethiopia. J. Ethnobiol Ethnomed 9(1), 32-34 (2013).

https://www.healthpromotion.ie/hpfiles/docs/HPM00406.pdf

Hendley JO, Wenzel RP, Gwaltney JM. Transmission of rhinovirus colds by self- inoculation $N$. Engl. J. Med. 288(26), 1361-1364 (1973).

Dick EC, Jennings LC, Mink KA.
Aerosol transmission of rhinovirus colds. J. Infec. Dis. 156(3), 442-448. (1987).

Winther B, Mc Cue K, Ashe K, Rubino JR, Hendley JO. Environmental contamination with rhinovirus and transfer to fingers of healthy individuals by daily life activity J. Med. Virol. 79(10), 1606-1610 (2007).

Gwaltney JM Jr, Hendley JO. Mechanisms of transmission of rhinovirus infections Epidemiol. Rev. 10(1), 242-258 (1988).

Farr BM, Hendley JO, Kaiser DL, Gwaltney JM. Two randomized, controlled trials of virucidal nasal tissues in the prevention of natural upper respiratory infections. Am. J. Epidemiol. 128, 1162-1172 (1988). 